\title{
Cervical Spondylosis in Nepalese Porters
}

\author{
Bista P', Roka YB' \\ 'National Neurosurgical Referral Centre, National Academy of Medical Sciences \\ Bir Hospital, Kathmandu, Nepal
}

\section{ABSTRACT}

Neck pain with or without radiculopathy and myelopathy is a very common problem in clinical practice. The incidence is believed to be higher in subgroups carrying load on their head. It has been reported in literature that radiographic spondylosis is appreciable in $25 \%$ to $50 \%$ of population by the age of 50 years and $75 \%$ to $85 \%$ by the age of 65 years.

One hundred and nineteen lateral X-rays of cervical spine were analyzed as case-control study in patients between 40 and 50 years age with the objective of finding out proportion of cervical spondylosis in this age group and difference in the prevalence between porters and non-porters.

Out of the 119 cases $54(45.4 .2 \%)$ were porters and 65 (54.6\%) were non-porters. There were 98 $(82.4 \%)$ males and $21(17.6 \%)$ females. The overall prevalence of radiological cervical spondylosis was $69(58 \%)$. The prevalence of cervical spondylosis was significantly lower $\left(x^{2}=14.795, p=0.0001\right)$ in porters in comparison to non-porters. The odds ratio was found to be $0.23(0.10,0.53)$ at $95 \%$ confidence interval indicating that portering significantly prohibited development of spondylosis.

This study concludes that the overall prevalence of cervical spondylosis in the Nepalese population is slightly higher than in the Caucasian and contrary to other studies there is significantly lower prevalence of such degeneration among the Nepalese porters.

Key words: cervical Spine, cervical spondylosis, head Injury, Nepalese porters

\section{INTRODUCTION}

In a study of diseases of the spine in South American Mummies several cases of cervical spondylosis were determined to be the result of an occupational disease resulting from carrying heavy loads on the back. These heavy loads were supported by wearing around the forehead a trumpline, known as a 'Capacho' exactly like the Nepalese porters do with 'Namlo'. If we assume that cervical spondylosis was the result of carrying heavy loads on the back in South American mummies, would it hold true in case of Nepalese porters. If, so how many proportion of these are symptomatic? Therefore this study was done to know the prevalence of cervical spondylosis is really high in our porters with radiological and clinical evidence. In order to find the prevalence of cervical spondylosis in general population a large pool of data would be needed, which would also require exposure to ionizing radiation of the asymptomatic study population for x-ray of cervical spine. However, comparison of the prevalence of cervical spondylosis between people who carry heavy loads on their back 
Bista et al. Cervical Spondylosis in Nepalese Porters

(porters) and these who do not, may reflect the differences in the prevalence.

The objectives of this study were to find out the prevalence of cervical spondylosis among non-porters and porters and its clinical significance, compare the significance of difference of cervical spondylosis among these two groups, to estimate the risk of developing cervical spondylosis due to carrying heavy loads on the back with the 'Namlo' in Nepalese porters and to find out proportion of patient with neurological symptoms due to cervical spondylosis.

\section{MATERIAL AND METHODS}

This is a case control prospective study done in patients with head injury attending to emergency department, Bir Hospital during May 2001 and April 2003. Ethical approval was taken from the Institute review board and consent was taken from the patients.

Lateral radiograph of all the patients with head injury requiring cervical spinal $\mathrm{X}$-ray were analyzed by the investigator and were verified by a consultant radiologist who was blinded about the occupation of the study subject. Finding of one of the following radiological features in the lateral radiograph of the cervical spine was considered as having spondylosis:

1. Sclerosis of interfacet joints

2. Presence of osteophytes

3. Narrowing of the disc spaces

4. AP diameter of spinal canal at C5 level $\leq 13 \mathrm{~mm}$

5. Loss of normal alignment of the cervical spine

All patients aged 40-50 were recruited with non-porters as case and porters as controls. Patients with definite evidence of cervical spinal injury were excluded from the study.

The data was analysed with the Statistical Package for Social Sciences (SPSS) version 11.0 for Windows. Chi square test done to see the level of significance between the prevalence of spondylosis in the porter and the non-porter. Odds ratio was calculated to estimate the risk factor.

\section{RESULTS}

A total of 119 lateral X-rays of cervical spine were collected over the period of two years. Sixty nine $(58 \%)$ of the studied radiographs showed one of the radiological evidence of spondylosis (Table 1). Out of these only $8(6.7 \%)$ had experienced symptoms related to spondylosis. There were $98(82.4 \%)$ male and 21 $(17.6 \%)$ female (Table 2).

There were 54 (45.4\%) porters and the rest of 65 $(54.6 \%)$ were non-porter. Only $17.6 \%$ (21) out of 54 porters showed the radiological evidence of spondylosis in contrast to $40.3 \%$ (48) non-porters (Table 3). The significance of difference in the prevalence of the spondylosis between the porters and non-porters was calculated by chi square test and found to be highly significant $\left(x^{2}=14.795, P=0.000\right) \quad(T a b l e$ 4). The odds ratio was found to be $0.23(0.10,0.53)$ at $95 \%$ confidence interval indicating that portering significantly prevented developing spondylosis.

The degenerative pattern i.e. sclerosis of interfacet joint, osteophyte formation and disc space narrowing were similar in both the group but, the alignment of cervical spine among porters were reported to be abnormal in 5 $(4.2 \%)$ subjects. The abnormality reported were loss of cervical lordosis and step up deformity between $\mathrm{C} 4 / \mathrm{C} 5$ and $\mathrm{C} 5 / \mathrm{C} 6$.

The anterior-posterior (AP) diameter of spinal canal at C5 ranged between 13 to $21 \mathrm{~mm}$ (mean $18.1 \mathrm{~mm}$ ) (Table 5).

There was no significant difference in the prevalence of cervical spondylosis between male and female $(x 2=1.124, P=0.335)$ (Table 6). There was no relation between years of portering and spondylosis at all (Table 7).

\section{DISCUSSION}

It has been estimated that radiographic spondylosis is appreciable in 25 to 50 percent of population by the age of 50 years which is lower than the $58 \%$ of our study group. ${ }^{2}$

Cervical spondylosis, spondylotic myelopathy, cervical herniated disc, cervical radiculopathy, cervical syndrome and cervicobrachial syndrome account for 0.8 to 0.9 percent of the discharges from hospital that does not emphasize neurology or neurological surgery and double that in hospitals where there is greater emphasis on neurosurgery. ${ }^{2}$ Our hospital record also shows comparable figures. ${ }^{1}$ The finding of only $6.7 \%$ significant spondylosis in the non-porter group is a unique finding in our study.

A study on the relationship between load carrying on the head and cervical spondylosis in Ghanaians showed that $63.6 \%$ of those who carry regular heavy load on their head had spondylosis in contrast to $36 \%$ of those who did not carry load on their head. ${ }^{6}$ Contrary to this finding only $17.6 \%$ of Nepalese porters were found to be having radiological evidence of spondylosis which is significantly $\left(x^{2}=14.79, P=0.000\right)$ lower than that of their counter part. Non-porter Nepalese have radiological evidence of spondylosis in $40.3 \%$. Studies by others have concluded that cervical spondylosis is not exclusively an ageing process but that regular heavy load carrying on the head plays etiological role, this is in contrast to this study showing there is no relation between the radiological evidence of spondylosis and 
Bista et al. Cervical Spondylosis in Nepalese Porters

years of portering $(P=0.767) .{ }^{6}$ Moreover it is evident from the present study that portering in the Nepalese traditional way positively protects from developing spondylosis (chi square $=0.1479, \mathrm{P}=0.0001$, Odds ratio $=0.23)(0.10,0.53)$.

In another study in Congolese wood bearers no relation was found between degenerative changes and wood carrying. However proportion of degenerative changes was greater in wood bearers $(41.4 \%)$ than in control group $(26.1 \%) .{ }^{5}$ The height of the vertebra from C3C6 and intervertebral discs of the wood bearers was significantly smaller than control group.In this study there was no significant difference in the pattern of degeneration among porters and non-porters but 5 $(4.5 \%)$ of the 54 porters showed step up deformity at C4/C5 and C5/C6 level, a phenomenon not seen in

Table 1. Radiological changes associated with spondylosis in porter and non-porter

\begin{tabular}{llll}
\hline \multirow{2}{*}{ Radiological Findings } & \multicolumn{3}{c}{ Profession } \\
& Porter & Non-porter & Total \\
\hline OA in IFJ & 9 & 35 & 44 \\
Osteophyte formation & 20 & 39 & 59 \\
Narrowing of Disc Space & 13 & 15 & 28 \\
Mal-alignment & 5 & & 5 \\
Spinal canal stenosis & & 1 & 1 \\
$<13$ mm at C5 & & & \\
\hline
\end{tabular}

Table 2. Sex wise frequency of porters and nonporters

\begin{tabular}{|c|c|c|c|}
\hline \multirow{2}{*}{ Sex } & \multicolumn{2}{|c|}{ Profession } & \multirow{2}{*}{ Tota } \\
\hline & Porter & Non-porter & \\
\hline Male & 48 & 50 & 98 \\
\hline Female & 6 & 15 & 21 \\
\hline Total & 54 & 65 & 119 \\
\hline
\end{tabular}

Table 3. Frequencies and percentage of spondylosis in porters and non-porters.

\begin{tabular}{llll}
\hline Spondylosis & $\begin{array}{l}\text { Profession } \\
\text { Porter }\end{array}$ & \multicolumn{2}{c}{ Notal } \\
& $21(17.6)$ & $48(40.3)$ & $69(58)$ \\
\hline Present & $33(27.7 .0)$ & $17(14.3)$ & $50(42)$ \\
Absent & $54(45.4)$ & $65(54.6)$ & $119(100)$ \\
\hline
\end{tabular}

the non-portering group. However none of those cases with this deformity had any clinical findings, although this form of deformity has been described as a feature of acute disc prolapse in literature. ${ }^{7}$

While carrying load on the head the weight transmission along the cervical spine takes place along the vertical axis of the spine. Carrying load on the back suspended with a 'Namlo' from the forehead passes through a different axis (needs to be confirmed by biomechanical studies). The compressive load approaches three times the weight of the head due to muscle co-activation forces in balancing the head in the neutral, relaxed posture this load increases during flexion and extension and other activities of daily living and is estimated to reach $1200 \mathrm{~N}$ in activities involving maximal isometric muscle efforts. ${ }^{4}$ To carry the heavy load on the back, Nepalese porters flex their cervical spine and there is maximal isometric contraction of neck muscles. This regular maximal isometric contraction of the neck muscle may play a significant role in protecting the degeneration of cervical spine in Nepalese porters. The superimposed lateral radiograph of cervical spine in neutral position $(B)$ and while carrying weight $(A)$ on the back with 'Namlo' (Figure 1).

Straightening of the normal cervical lordosis and the step up deformity seen in Nepalese porters may be a compensatory mechanism to over come the flexion of the cervical spine required to carry heavy weight on their back.

In conclusion the overall prevalence of cervical spondylosis in the Nepalese population is slightly higher

Table 5. Showing the AP diameter of spinal canal at C5 level.

\begin{tabular}{ll}
\hline AP Diameter at C5 in $\mathbf{~ m m}$ & Frequency \\
\hline 13 & $1(0.8 \%)$ \\
15 & $6(5 \%)$ \\
16 & $9(7.6 \%)$ \\
17 & $24(20.2 \%)$ \\
18 & $45(37.8 \%)$ \\
19 & $6(5 \%)$ \\
20 & $26(21.8 \%)$ \\
21 & $2(1.7 \%)$ \\
Total & $119(100 \%)$ \\
\hline
\end{tabular}

Table 4. Spondylosis in porters and non-porters and calculation of chi square value and odds ratio

\begin{tabular}{|c|c|c|c|c|c|c|}
\hline \multirow[b]{2}{*}{ Spondylosis } & \multicolumn{2}{|c|}{ Profession } & \multirow[b]{2}{*}{$X^{2}$} & \multirow[b]{2}{*}{ df } & \multirow{2}{*}{$\mathbf{P}$ value } & \multirow{2}{*}{$\begin{array}{c}\text { Odds ratio } \\
\text { (95\% confidence interval) }\end{array}$} \\
\hline & Porter & Non-porter & & & & \\
\hline Present & 21 & 48 & \multirow[b]{2}{*}{14.795} & \multirow[b]{2}{*}{1} & \multirow[b]{2}{*}{0.0001} & 0.23 \\
\hline Absent & 33 & 17 & & & & $(0.10-0.53)$ \\
\hline
\end{tabular}


Bista et al. Cervical Spondylosis in Nepalese Porters

Table 6. Significance of difference in the prevalence of cervical spondylosis in male and female.

\begin{tabular}{|c|c|c|c|c|c|}
\hline \multirow[b]{2}{*}{ Spondylosis } & \multicolumn{2}{|c|}{ Sex } & \multirow[b]{2}{*}{$x 2$} & \multirow[b]{2}{*}{$P$ value } & \multirow[b]{2}{*}{ Remarks } \\
\hline & Male & Female & & & \\
\hline Present & 59 & 10 & \multirow{2}{*}{1.124} & \multirow{2}{*}{0.335} & \multirow{2}{*}{ Not significan } \\
\hline Absent & 39 & 11 & & & \\
\hline
\end{tabular}

Table 7. Spondylosis against the year of portering.

\begin{tabular}{|c|c|c|c|}
\hline \multirow{2}{*}{ Year of Portering } & \multicolumn{2}{|c|}{ Spondylosis } & \multirow{2}{*}{ Total } \\
\hline & Present & Absent & \\
\hline 8 & 1 & & 1 \\
\hline 9 & & 1 & 1 \\
\hline 10 & 3 & & 3 \\
\hline 11 & & 1 & 1 \\
\hline 12 & 1 & 1 & 2 \\
\hline 13 & 1 & 1 & 2 \\
\hline 15 & 1 & 2 & 3 \\
\hline 17 & 3 & 2 & 5 \\
\hline 18 & 5 & 2 & 7 \\
\hline 19 & & 1 & 1 \\
\hline 20 & & 4 & 4 \\
\hline 21 & & 2 & 2 \\
\hline 22 & 1 & 1 & 2 \\
\hline 23 & & 5 & 5 \\
\hline 24 & & 1 & 1 \\
\hline 25 & & 2 & 2 \\
\hline 26 & 1 & & 1 \\
\hline 27 & 1 & 2 & 3 \\
\hline 29 & & 1 & 1 \\
\hline 30 & 3 & 2 & 5 \\
\hline 31 & & 2 & 2 \\
\hline Total & 21 & 33 & 54 \\
\hline
\end{tabular}

than in the Caucasian. However there is significantly lower prevalence of such degeneration among the Nepalese porters. Carrying heavy load on the back with 'Namlo' suspended from the head requiring isometric flexion of the neck significantly reduce the risk of spondylosis among them.

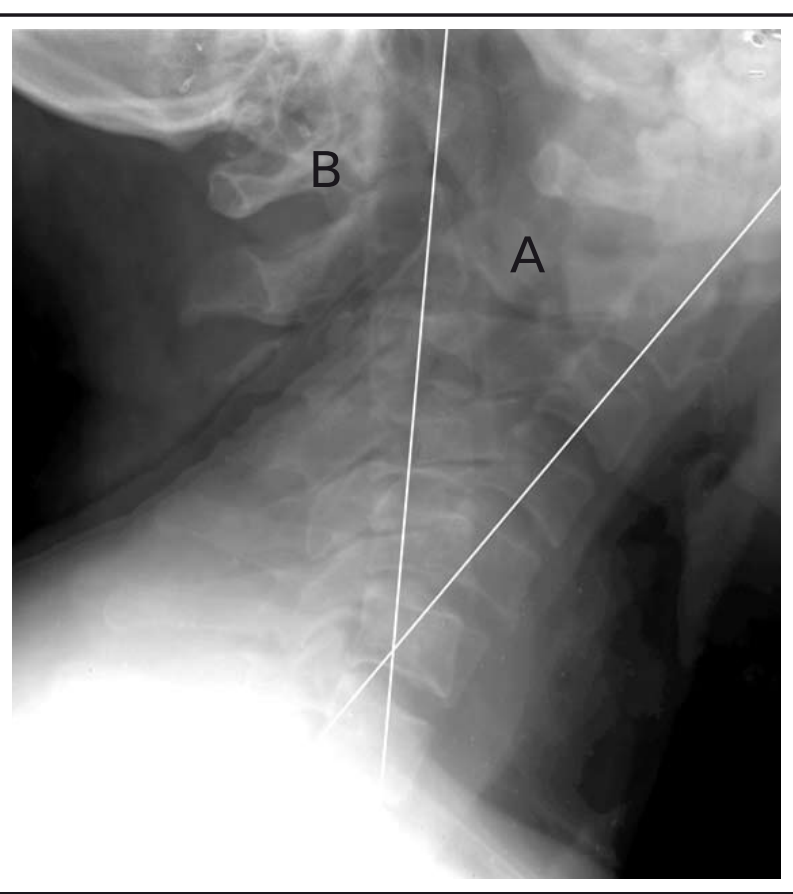

Figure 1. Superimposed lateral radiographs with (A) and without Namlo (B). The difference of axes is 210

Since data was collected only from head injured patient with indication for cervical spine X-ray, in the 40-50 years of age group. Moreover the spondylosis usually starts at about 40 years in general population and at this age porters would have portered at least for 10 years. Majority of these porters would give up portering by 50 years of age. Hence, the finding may not represent the true trend of cervical spondylosis in general population.

\section{REFERENCES}

1. Sharma GR, Devkota UP. Anterior Cervical Discectomy and Fusion; A retrospective study of 68 cases. Presented in the 3rd International Conference of ICS, Nepal, March 2002.

2. Key CA, Gay Hosp Rep, 3:17, 1838 (sited in Youmans) by B. Ehni, G. Ghni and R. H. Patterson. Jr. Chapter 99, p. 28782913.

3. Gerszten PC, Gerszten E, Allison MJ. Diseases of the spine in South American Mummies. Neurosurgery 2001 Jan;48(1):208-13.
4. Moroney SP, Schultzy AB, Millar JAA. Analysis and measurement of neck load. J Orthop Res 1988;6:713-20.

5. Bell GH, Dunbar O, Beck JS, Gibb A. Variation in strength of vertebra with age and their relation to osteoporsis. Calcif Tissue Res 1967;1:75-86.

6. Jumah KB, Nyame PK. Relationship between load carrying on the head and cervical spondylosis in Ghanaians. West Afr J Med 1994;13(3):181-2.

7. Sutton D. (Editors). A textbook of Radiology and Imaging. 4th ed. Churchil Livingstone; 1987. p. 114. 